\title{
Status Epilepticus as Presenting Symptom of Fahr's Disease
}

\author{
Arvind Kumar Mishra, Rohin Saini, Rohit Anand \\ Department of Medicine, King George Medical University, Lucknow, Uttar Pradesh, India.
}

\section{Corresponding Author:}

Dr. Arvind Kumar Mishra

Email: anuarvindmishra@yahoo.com

This is an Open Access article distributed under the terms of the Creative Commons Attribution License (creativecommons.org/ licenses/by/3.0).

Received Accepted

Published

October 9, 2018

January 14,2019

January 20, 2019

\begin{abstract}
Background: Fahr syndrome is a rare neuro-degenerative disorder characterized by symmetrical, bilateral calcifications in the basal ganglia, nucleus gyrus and cerebral cortex. It leads to cell loss in areas controlling movement and has build up of calcium concretions in the brain that can trigger epilepsy. Such intra-cranial calcifications are often but not always associated with chronic hypoparathyroidism and can have thyroid dysfunction too. Case Report: We present a case of 14 year old female presenting in status epilepticus previously been diagnosed as epilepsy, compliant with treatment for same since one year. Computed tomography head revealed diffuse cerebral calcifications in dentate nucleus with striato-pallidium calcifications. She was treated with intravenous calcium and antiepileptics and made remarkable recovery. Conclusion: This case highlights a unique and rare presentation of Fahr syndrome presenting with status epilepticus which subsided with treatment with intravenous calcium and antiepileptics
\end{abstract}

Keywords: Basal Ganglia, Brain, Epilepsy, Neurodegenerative Diseases, Status Epilepticus.

\section{Introduction}

Fahr syndrome is a rare neuro-degenerative disorder characterized by symmetrical, bilateral calcifications in the basal ganglia, nucleus gyrus and cerebral cortex. It leads to cell loss in areas controlling movement and has build up of calcium concretions in the brain that can trigger epilepsy. Such intra-cranial calcifications are often but not always associated with chronic hypoparathyroidism and can have thyroid dysfunction too [1]. The relationship between intra-cranial calcification, neurological abnormalities and cognitive deficits in this disorder is speculative. This case are highlights a unique presentation probably first in the literature of Fahr's syndrome to present with generalized tonic clonic seizure and status epilepticus which subsided with treatment with intravenous calcium and anti-epileptic.

\section{Case Report}

A 14 year old right handed female was admitted in the emergency department of King George's Medical University with complaints of multiple episodes of seizures without regaining consciousness for the past three days. The patient's attendant states that she has had two similar previous episodes which subsided after 2-3 days however she has never been investigated for the same. The attendants claim that she always has an intense headache preceding the episodes of seizures but becomes normal after two days so they used to isolate the child during her episodes. These episodes had no precipitating factors. They stated that she has difficulty in learning but can read write and interact with her peers but studies in a class three grade. She also had mild difficulty in articulation of speech and has a husky voice. She had no previous 
medical history of trauma, cerebrovascular accident, paresthesia, muscle cramps or tetany. No family history of stroke or movement disorders was elicited. On examination, her Glasgow coma scale was $E_{1} V_{1} M_{1}$ with bilaterally reactive pupils and mute plantar response. Her BP was 90/60 mm $\mathrm{Hg}$ right arm supine and had a heart rate of 140 beats per minute. Her tone in upper and lower limb was decreased with normal upper and lower limb reflexes. Chvostek and Trousseau signs, tremor, and rigidity were absent. No extra-pyramidal features such as ataxia or athetosis were present. No typical findings of Albright's hereditary osteodystrophy were observed. Her GCS slowly improved to $\mathrm{E}_{3} \mathrm{~V}_{2} \mathrm{M}_{5}$ and she still persisted in a state of altered sensorium till day three.

Her routine investigations were sent which revealed hemoglobin: $9.5 \mathrm{~g} / \mathrm{dL}$ (12-15), total leukocyte count: 6700 cells $/ \mathrm{mm}^{3}$ (4000$12000)$, differential count $\mathrm{N}_{76} \mathrm{~L}_{20}\left(\mathrm{~N}_{40-80}, \mathrm{~L}_{20-40}\right)$, mean corpuscular volume: $77.9 \mathrm{fl}$ (80-100), mean corpuscular hemoglobin: 26.9 pg (27-32), platelets: $0.7 \mathrm{lac} / \mathrm{mm}^{3}$ (1.5-3.5), random blood sugar: 135 mg/dL (70-120), sodium: $138 \mathrm{mmol} / \mathrm{L}$ (136-146), potassium: $2.3 \mathrm{mmol} / \mathrm{L}$, blood urea: $24.1 \mathrm{mg} / \mathrm{dL}$ (10-46), serum creatinine: $0.6 \mathrm{mg} / \mathrm{dL}(0.6-1.4)$, total bilirubin: $0.39 \mathrm{mg} / \mathrm{dL}(0.3-1.0)$, direct bilirubin: 0.2 $\mathrm{mg} / \mathrm{dL}(0-0.4)$, aspartate aminotransferase: $45 \mathrm{IU} / \mathrm{L}$ (0-40), alanine aminotransferase: $21 \mathrm{IU} / \mathrm{L}$ (0-40), alkaline phosphatase: 277 IU/L (50-240), serum protein: $5.6 \mathrm{gm} / \mathrm{dL}(6.0-8)$, serum albumin: $3.8 \mathrm{~g} / \mathrm{dL}$
(3.5-5.5), prothrombin time: 15.8 seconds (10-25), and INR 1.23 (1.0-2.0). Computed tomography head showed evidence of multiple calcifications seen in bilateral basal ganglia, bilateral periventricular region, bilateral fronto-parietal region in white matter and bilateral dentate nucleus [Fig.1]. Electroencephalogram was within normal limits. Her biochemical tests showed total calcium: $6.3 \mathrm{mg} /$ $\mathrm{dL}$ (9-11) and ionic calcium: $0.7 \mathrm{mmol} / \mathrm{L}(0.9-1.2)$, serum phosphate: $5.9 \mathrm{mg} / \mathrm{dL}(2.5-4.5)$ and serum magnesium: $2.94 \mathrm{mg} / \mathrm{dL}$ (1.4-2.6), vitamin D: 14.6 $\mathrm{ng} / \mathrm{mL}(50-80)$ and serum parathormone: $8.7 \mathrm{pg} / \mathrm{ml}$ (10-65). Electrocardiogram and two dimensional echocardiography was within normal limits and showed no cardiac abnormalities. Fundus of both eyes showed normal optic disc with no obvious papilledema. High resolution ultrasonography neck showed diffuse atrophic thyroiditis. Her thyroid profile was: $\mathrm{T}_{3}: 0.5 \mathrm{ng} / \mathrm{dL}(0.8-0.18), \mathrm{T}_{4}: 8.2 \mathrm{mcg} / \mathrm{dL}$ (4.6-12), TSH: $94.9 \mathrm{mcgIU} / \mathrm{mL}(0.5-6), \mathrm{FT}_{3}: 1.5$ $\mathrm{pg} / \mathrm{mL}(2.3-6.1), \mathrm{FT}_{4}: 0.9 \mathrm{ng} / \mathrm{dL}(0.7-1.9)$ and antithyroid peroxidase: $1804.41 \mathrm{IU} / \mathrm{mL}(0-6)$.

She was admitted and started on injection phenytoin however she still had break through seizures and injection valproate and injection levetiracetam were added. She maintained a state of post-ictal altered sensorium and was started on intravenous calcium after her serum parathormone levels were found to be low and was started with $0.5 \mathrm{mcg}$ calcitriol and $1000 \mathrm{mg}$ calcium carbonate (oral, daily). She was even advised for subcutaneous

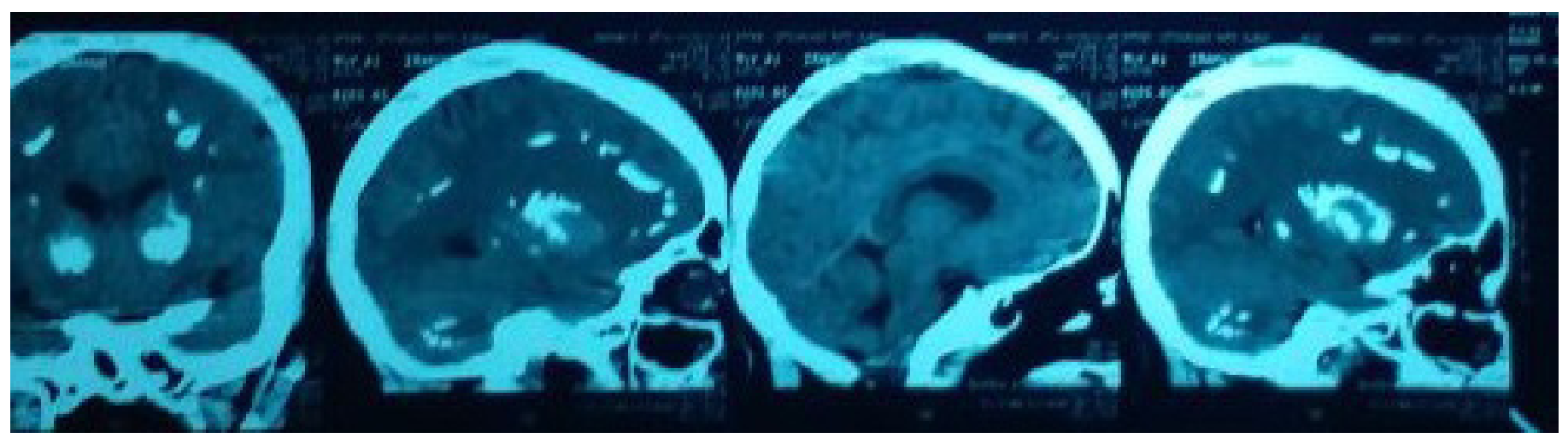

Fig.1: NCCT head of patient on day of admission. 
human parathormone but was deferred due to financial conditions.

She eventually regained full consciousness and was tapered down from three to two antiepileptics with regular supplementation of vitamin $\mathrm{D}$ and calcium and was discharged after a five day seizure free interval of three days. She is currently been followed up in medicine out-patient basis [Fig.2] and has been on a seizure free period for one year and has been on one antiepileptic phenytoin and calcium and vitamin $\mathrm{D}_{3}$ supplementations.

\section{Discussion}

Fahr syndrome is a degenerative neurological disorder whose prevalence is probably less than $0.5 \%$. It doesn't have any single known etiology but is the final manifestation in multiple disorders [2]. These causes include tumor (astrocytomas), hypoxic and vascular insults to the brain, endocrinal abnormalities such as hypoparathyroidism, pseudo-hypoparathyroidism, hyper-parathyroidism, toxins like carbon monoxide and lead intoxication along with metabolic and degenerative causes [3,4]. Literature describes various manifestations of Fahr syndrome ranging from being completely asymptomatic to features of basal ganglia involvement like movement disorders, tics, stereotypical behavioral abnormalities, hallucinations, delusions etc. However rarely has it been reported with a presentation of status epilepticus which was largely remediable by calcium supplementation and anti-epileptic [5]. It is still yet to be established whether the calcification is dystrophic or metastatic in nature. Fahr's syndrome clinical manifestations can vary [6].

This case highlights the rare manifestation of Fahr's disease presenting with generalized tonic clonic seizure. The seizures in such patients may be due to abnormalities in calcium metabolism or hypocalcemia, dysfunction of cortico-basal connection, concretions of calcium acting as epileptic irritants for the white matter. It has also been suggested that gliosis and inflammation of grey and white matter facilitates calcification in the striopallio-dentate system as and when calcium metabolism abnormalities develop $[7,8]$.

\section{Conclusion}

We would like to conclude by stating that apart from highlighting the rarity of presentation of Fahr's disease with status epilepticus, investigations for calcium, magnesium and phosphate levels should

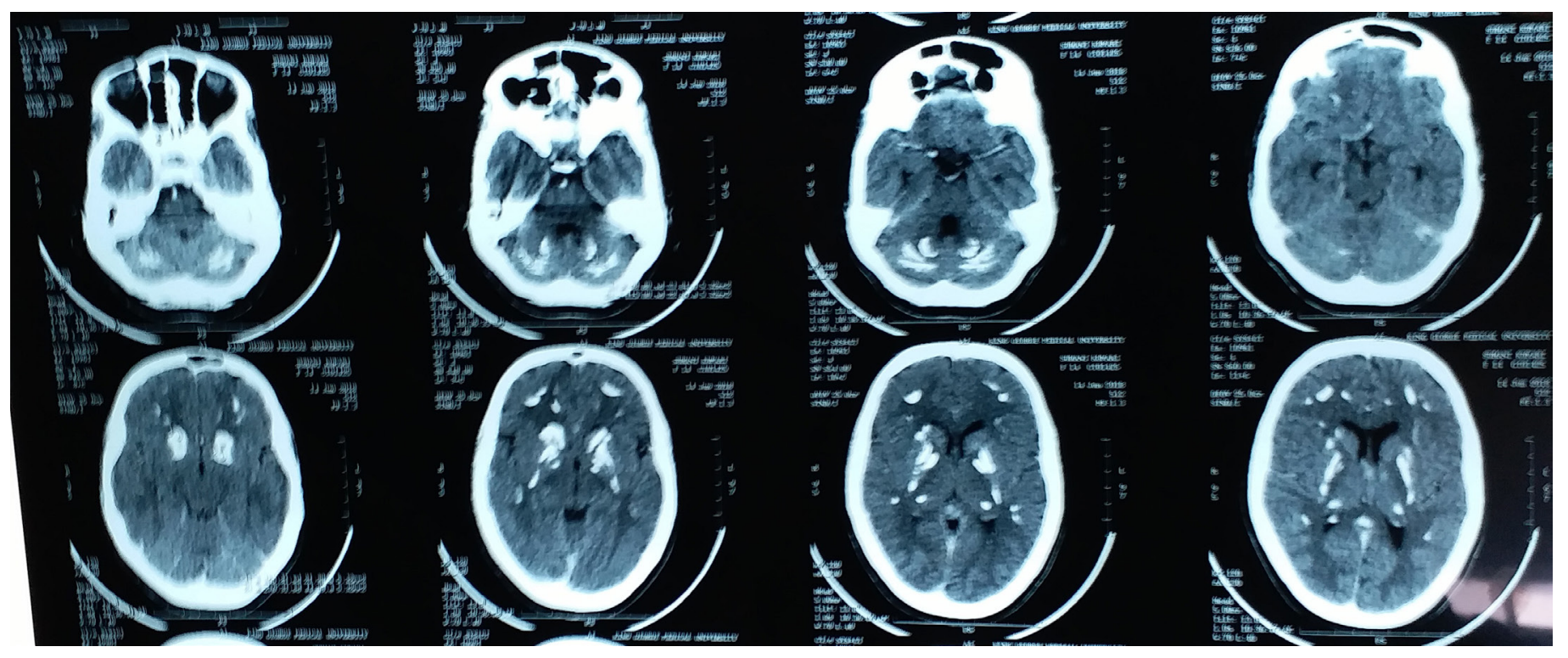

Fig.2: NCCT head of patient after 6 months on treatment. 
be carried out in all cases of status epilepticus and if abnormality is detected, it should be corrected at the earliest. Patients with radiological findings suggestive of Fahr syndrome should also be investigated for serum parathormone and thyroid profile assay as concurrent abnormalities have been seen and correcting the impaired calcium phosphorus metabolism along with thyroxine supplementation often leads to considerable improvement in overall health of the patient. As there is no cure or a standard course of treatment for Fahr's disease, failure to correct these metabolic abnormalities can lead to variable prognosis.

Contributors: AKM: manuscript editing, patient management; RS, RA: manuscript writing, literature search, patient management. AKM will act as guarantor. All authors approved the final version of this manuscript.

Funding: None; Competing interests: None stated.

\section{References}

1. Sava A, Dumitrescu G, Haba D, Hodorog D, Mihailov C, Sapte E. The Fahr syndrome and the chronic lymphocytic thyroiditis. Rom J Morphol Embryol. 2013;54:195-200.

2. Abubakar SA, Saidu S. Idiopathic bilateralstrio-pallidodentate calcinosis (Fahr's disease): a case report and review of the literature. Ann Afr Med. 2012;11:234-237.

3. Saleem S, Aslam HM, Anwar M, Saleem M, Saleem A, Rehmani MA. Fahr's syndrome: literature review ofcurrent evidence. Orphanet Journal of Rare Diseases. 2013;8:156.

4. Ashtari F, Fatehi F. Fahr's disease: variable presentations in a family. Neurol Sci. 2010;31:665-667.

5. Modrego PJ, Mojonero J, Serrano M, Fayed N. Fahr's syndrome presenting with pure and progressive presenile dementia. Neurol Sci. 2005;26:367-369.

6. Kummer A, de Castro M, Caramelli P, Cardoso F, Teixeira AL. Severe behavioral changes in a patient with Fahr's disease. Arq Neuropsiquiatr. 2006;64:645-649.

7. Bruyn GW, Bots GTAM, Staal A. Familial bilateral vascular calcification in the central nervous system. Psychiatr Neurol Neurochir. 1964;67:342-376.

8. Margolin D, Hammerstad J, Orwoll E, McClung M, Calhoun D. Intracranial calcification in hyperparathyroidism associated with gait apraxia and parkinsonism. Neurology (Minneap). 1980;30:10051007. 